\title{
Meiofauna de praia arenosa da llha Anchieta, São Paulo: I. Fatores físicos
}

\author{
Liliana R. A. MEDEIROS
}

Instituto de Biociências da Universidade de São Paulo

(Caixa Postal 20520, 0131-970 São Paulo, SP, Brasil)

- Abstract: As part of a meiofaunistic research, this paper describes some relevant physical factors of a moderately exposed sandy beach located at Anchieta Island $\left(23^{\circ} 32^{\prime} \mathrm{S}-45^{\circ} 04^{\prime} \mathrm{W}\right)$, Brazil. Reflective and dissipative domains could be recognized. These domains differ by the hydrodynamic forces to which they are submitted, grain size and sorting characteristics, pore space available to interstitial life, temperature, water and organic contents, relative stability, isolation from the adjacent marine system, and historical aspects.

Descriptors: Beaches, Sediment texture, Interstitial environment, Meiobenthos, Abiotic factors, Ilha Anchieta: SP, Brazil.

- Descritores: Praias, Textura de sedimento, Entremarés, Meiobentos, Fatores abióticos, Ilha Anchieta: SP.

\section{Introdução}

Este trabalho é parte de uma série sobre a meiofauna da Praia Grande, Ilha Anchieta, SP. Medeiros (1987) abordou aspectos gerais da composição e abundância da meiofauna desta praia, comparando-os com outras áreas de clima tropical, subtropical e temperado quente. $\mathrm{O}$ presente trabalho detalha a distribuição de temperatura, salinidade, $\mathrm{pH}$, granulometria, porosidade, teores de água e matéria orgânica, saturação, declividade, caracterizando o ambiente experimentado pela meiofauna.

A importância de diversos fatores abióticos na distribuição e adaptação da meiofauna foi tratada por vários autores (p. ex. Jansson, 1971; Pollock, 1971; Wieser, 1975; Vernberg \& Coull, 1981; McLachlan, 1983; Palmer, 1988; Medeiros, 1990). Dentre os fatores rotineiramente avaliados em estudos ecológicos (Hulings \& Gray, 1971; Giere et al., 1988), as características do sedimento têm sido enfatizadas, seja pela relativa facilidade de obtenção das medidas, seja porque condicionam uma série de outros fatores. Sem constituir exceçāo, o presente estudo destaca as características do depósito na determinaçāo das feiçōes ambientais.

\section{Área de estudo}

As amostragens efetuaram-se na Praia Grande da Ilha Anchieta $\left(23^{\circ} 32^{\prime} \mathrm{S}-45^{\circ} 04^{\prime} \mathrm{W}\right.$, Fig. 1), pertencente ao município de Ubatuba, litoral nordeste do Estado de São Paulo. Com área aproximada de $10 \mathrm{~km}^{2}$ a ilha, integrada ao domínio das áreas tropicais atlânticas florestadas (Ab'Sáber, 1970), corresponde a um esporão emerso da Serra do Mar, com rochas graníticas cortadas por diques de diabásio e sedimentos praiais Holocênicos (Cruz, 1974; Suguio \& Martin, 1978; Maldonado et al., 1987). A face sudeste constitui-se por um costão quase contínuo, sob forma de escarpa, a norte, recortada, forma a Enseada das Palmas (Cruz, op. cit., Forneris, 1969, Amaral, 1980), onde se localiza a praia estudada (Fig. 2).

Dados climáticos da região de Ubatuba (233's $45^{\circ} 07^{\prime} \mathrm{W}$, altitude $25 \mathrm{~m}$ ), analisados por Silva (1984), dão índices pluviométricos altos: em média $2085 \mathrm{~mm}$ anuais, $100 \mathrm{~mm}$ mensais no período mais seco (maio-agosto) e 230 $\mathrm{mm}$ mensais no mais úmido (novembro-março). A alta umidade relativa do ar apresenta médias mensais bastante constantes, ao redor de $85 \%$. As médias mensais de temperatura do ar estão em torno de $20-26^{\circ} \mathrm{C}$; médias mensais de máximas e mínimas ficam em torno dos $20-33^{\circ} \mathrm{C}$ e $15-24^{\circ} \mathrm{C}$, respectivamente. 


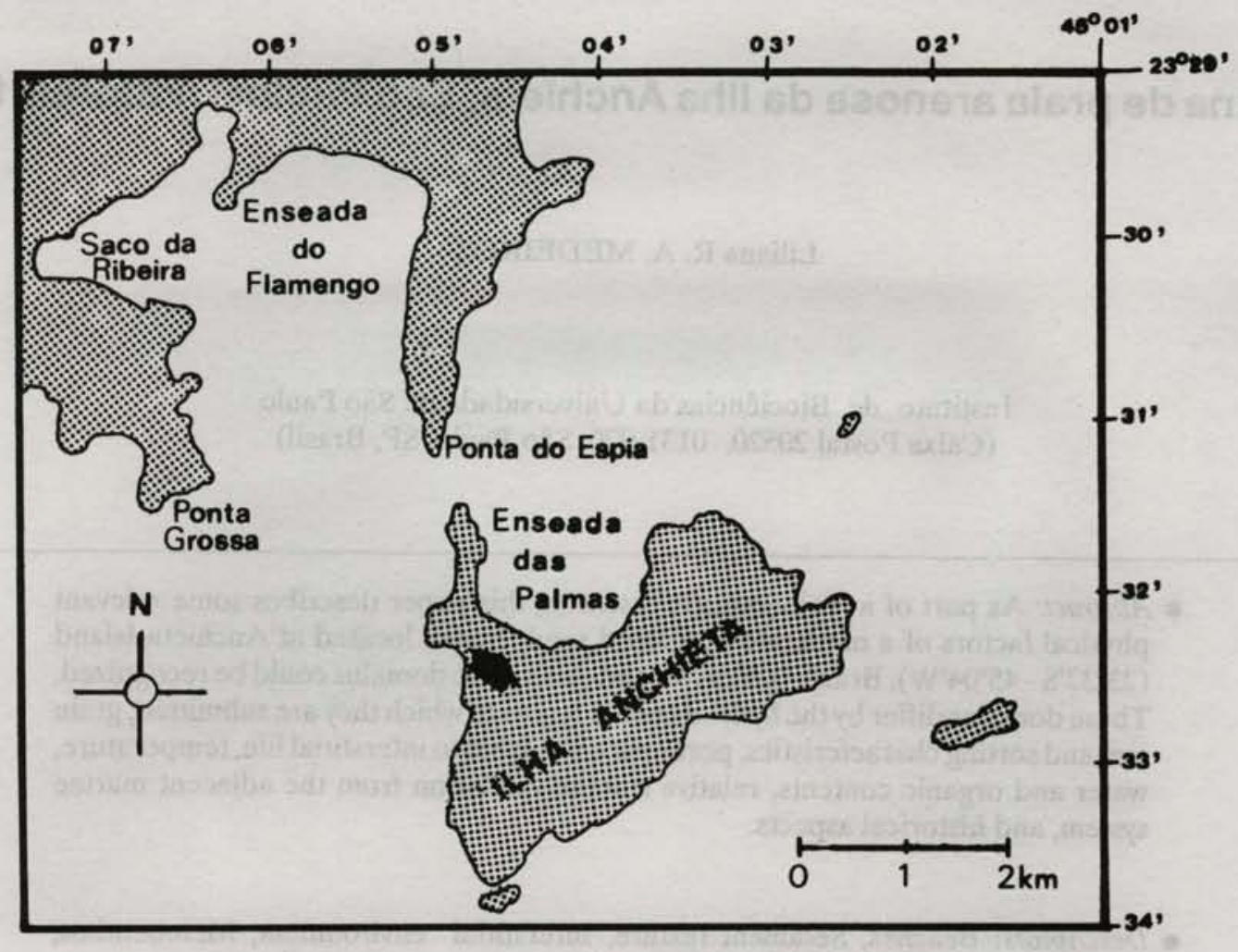

Fig. 1. Setor $23^{\circ} 29^{\prime}-23^{\circ} 34^{\prime} S$ - $45^{\circ} 01^{\prime}-45^{\circ} 07^{\prime} \mathrm{W}$ da costa nordeste do Estado de São Paulo.

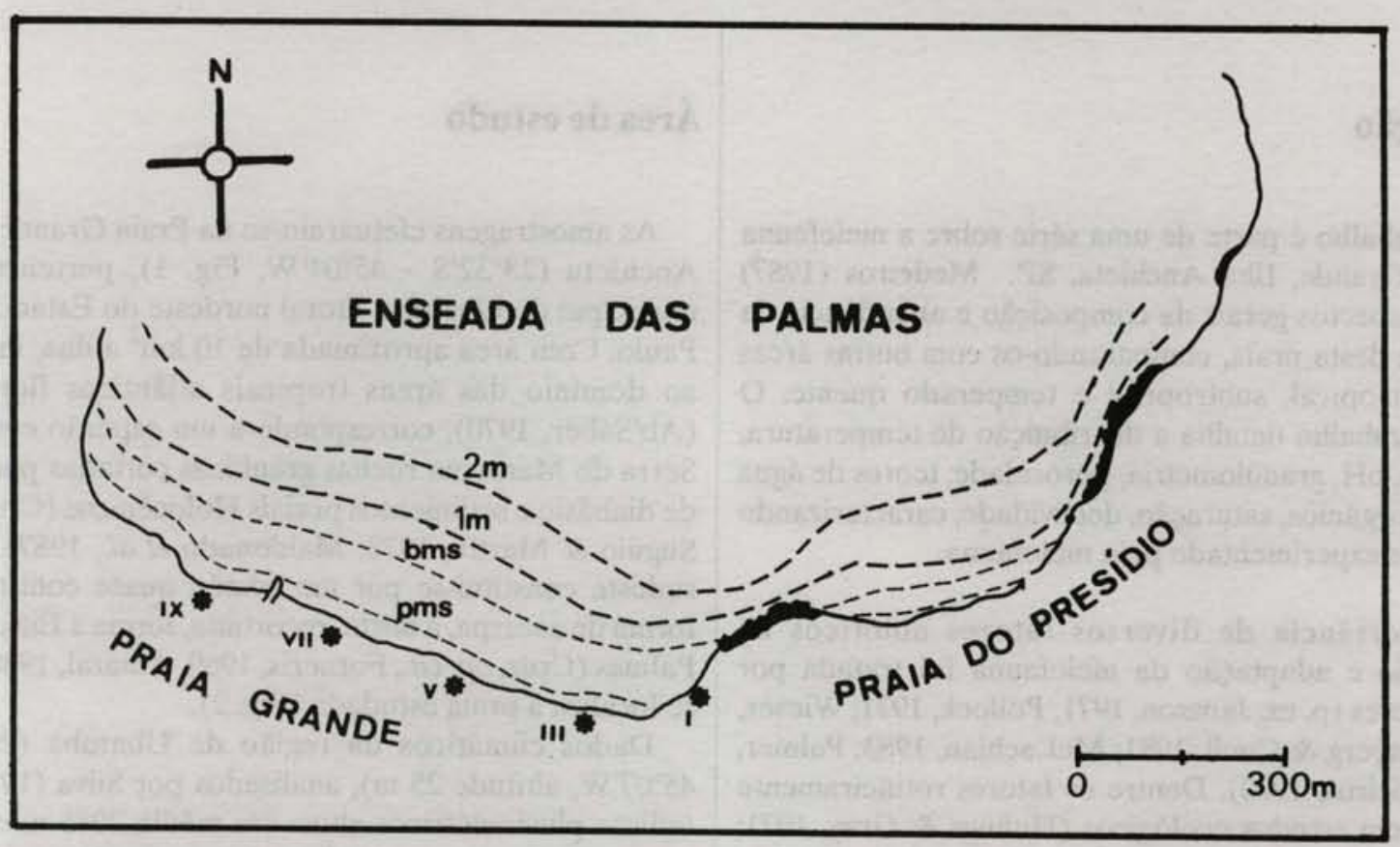

Fig. 2. Enseada das Palmas mostrando, na Praia Grande, a localização das cinco transeções amostradas (baseado em Amaral, 1980). 
O vento predominante na ilha é o de leste que atinge, principalmente, a face sudeste; ventos de norte e nordeste sāo pouco freqüentes (FUMEST, 1974). Ondas provenientes de leste atingem a Enseada das Palmas, que fica abrigada das ondas de sul e sudoeste. As últimas, quando atingem a ilha, são ondas refratadas de baixa energia (Signorini, 1974). As marés da regiâo de Ubatuba, semi-diurnas com desigualdade diurnal, foram estudadas por Mesquita \& Harari (1983). Castro Filho et al. (1987) avaliaram as condiçōes hidrográficas.

\section{Material e métodos}

A área de prospecção situou-se entre a linha d'água na maré baixa do período e o início da vegetação terrestre. Cinco transeçōes, perpendiculares à linha d'água e distantes entre si $200 \mathrm{~m}$, foram estudadas (Fig. 2). Três destas transeçōes, situadas na metade leste (T I, T III) ou central (T V) da praia, foram amostradas em fevereiro de 1984, e duas situadas a oeste (T VII, T IX), em julho do mesmo ano; neste mês também se repetiu a amostragem da transeção central ( $\mathrm{T}$ V7/84).

Ao longo de cada transeção, estabeleceram-se pontos de amostragem a intervalos de $3 \mathrm{~m}$, onde foram tomadas medidas de temperatura do sedimento (termômetro de mercúrio), $\mathrm{pH}$ (papel indicador universal 0-14, Merck) e coletadas amostras de sedimento. O perfil de cada transeçāo foi obtido por nivelamento, o desnível medido a cada metro (Montano-Ley \& Gutierrez-Estrada, 1987).

A análise granulométrica foi feita por peneiramento seco (Suguio, 1973) e, como a fração menor que $0,062 \mathrm{~mm}$ foi sempre muito reduzida $(0-0,5 \%)$, não se procedeu à análise por pipetagem. Os parâmetros de análise estatística, obtidos com os dados na escala $\varnothing$ de Krumbein (Suguio, op. cit.), foram calculados pelas fórmulas de Folk \& Ward (1957).

Os teores de água foram obtidos por secagem em estufa a $70^{\circ} \mathrm{C}$ até a estabilização do peso e a porosidade determinada pelo método recomendado por Amoureux (1966). Já que as medidas de teor da água foram obtidas em porcentagem do peso, para determinação da saturação (porcentagem de poros preenchidos por água na situação de coleta), o volume de poros de cada amostra foi recalculado relacionando-o ao peso do sedimento. $O$ diâmetro dos poros foi calculado, pela equação de Koseny-Carmen (Crisp \& Williams, 1971), para sedimentos com coeficiente de seleção próximo a 1.

Nas amostras destinadas à análise do teor de matéria orgânica, a fixação foi feita com formol comercial pingado sobre a amostra até a concentração aproximada de $4 \%$. Subamostras de $10 \mathrm{~g}$ defaunadas, dessalinizadas, desidratadas e desprovidas de partículas maiores que 2 mm tiveram o teor de matéria orgânica avaliado pelo método de ignição recomendado por Retière (1968).

\section{Resultados e discussão}

Segundo dados climáticos do posto meteorológico do laboratório do Instituto de Pesca (Praia do Presídio, Fig. 2), nos dias de coleta de verão (16, 17 e 19/2/1984), as temperaturas atmosféricas máximas oscilaram entre 28 e $31,5^{\circ} \mathrm{C}$, as mínimas, entre 25 e $30^{\circ} \mathrm{C}$. As amplitudes térmicas diárias foram de $0,5-3,5^{\circ} \mathrm{C}$. A água do mar teve temperaturas entre $22-28^{\circ} \mathrm{C}$. A umidade relativa do ar oscilou entre $84-100 \%$, registrando-se pluviosidade às 8:00h do dia 19.

$\mathrm{Na}$ coleta de inverno $(28,29$ e $30 / 7 / 1984)$, as temperaturas atmosféricas máximas estiveram entre $21 \mathrm{e}$ $23^{\circ} \mathrm{C}$, as mínimas entre $18 \mathrm{e} 21^{\circ} \mathrm{C}$. As amplitudes térmicas diárias foram de $1,5-3,0^{\circ} \mathrm{C}$. As temperaturas marinhas oscilaram entre $19-21,5^{\circ} \mathrm{C}$. A umidade relativa do ar foi de 81 a $100 \%$, com chuvas registradas às $8: 00 \mathrm{~h}$ do dia 29.

As amplitudes térmicas foram, pois, ligeiramente maiores no verão. As diferenças térmicas entre os dois períodos de amostragem foram relativamente grandes, mas näo atípicas para as características climáticas da região.

\section{Hidrodinamismo, declividade, sedimentos}

A largura da praia emersa (Tab. 1, Fig. 3) decresceu de T I (57 m) a T VII (21 m), aumentando em T IX (33 m). A declividade foi mais acentuada na transeção central, suavizando-se daí para leste e oeste (Fig. 3). As razōes de desnível (m) por extensão da transeção (m) foram de aproximadamente $1 / 51,5 \mathrm{em} \mathrm{T} \mathrm{I,} \mathrm{1/11,5} \mathrm{em} \mathrm{T} \mathrm{III,} \mathrm{1/9} \mathrm{em} \mathrm{T}$ V, 1/13 em T V7/84, 1/14 em T VII, 1/20 em T IX. A transeção $I$, de menor declividade, apresentou irregularidades topográficas, com depressão acentuada entre 36 e $51 \mathrm{~m}$ (Fig. 3).

A declividade tendeu a ser, geralmente, mais abrupta na porção superior da praia, mas em T IX, essa tendência não ocorreu, e a declividade acentuou-se a taxas quase constantes em toda sua extensâo. Deste modo, T IX foi a transeção que apresentou declividade mais acentuada na metade inferior da praia, seguindo-se T V e T III.

De um modo geral, os sedimentos praiais tenderam a tornar-se mais grossos com a proximidade do limite terrestre e de leste para oeste (Tab. 1). 
Tabela 1. Fatores abióticos, parâmetros granulométricos, obtidos ao longo das transeçöes I-IX

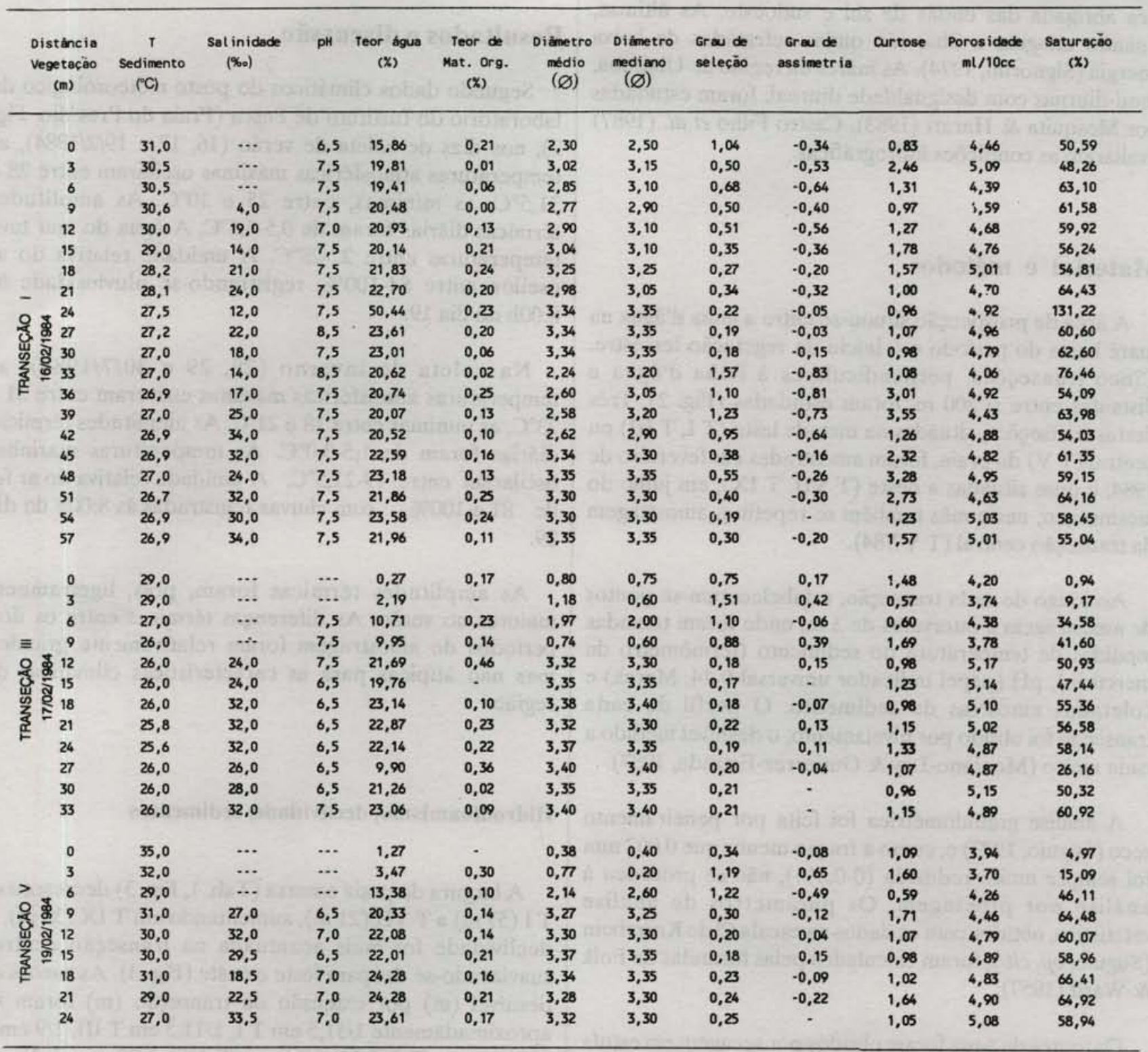

Continua 
Tabela 1. Continuação

\begin{tabular}{|c|c|c|c|c|c|c|c|c|c|c|c|c|}
\hline $\begin{array}{c}\text { Distáncia } \\
\text { Vegetaçào } \\
\text { (m) }\end{array}$ & $\begin{array}{c}T \\
\text { Sedimento } \\
\text { (PC) }\end{array}$ & $\begin{array}{l}\text { Sal inidade } \\
\text { (\%०) }\end{array}$ & pH & $\begin{array}{c}\text { Teor água } \\
(x)\end{array}$ & $\begin{array}{l}\text { Teor de } \\
\text { Mat. Org. } \\
\text { (x) }\end{array}$ & $\begin{array}{l}\text { Diămetro } \\
\text { médio } \\
\text { (ஜ) }\end{array}$ & $\begin{array}{l}\text { Diămetro } \\
\text { mediano } \\
(\varnothing)\end{array}$ & $\begin{array}{l}\text { Grau de } \\
\text { seleçáo }\end{array}$ & $\begin{array}{l}\text { Grau de } \\
\text { assimetr ia }\end{array}$ & Curtose & $\begin{array}{c}\text { Porosidade } \\
\text { ml/10cc }\end{array}$ & $\begin{array}{c}\text { Saturaçao } \\
\text { (x) }\end{array}$ \\
\hline \multirow{9}{*}{ 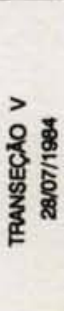 } & & & $b^{3}$ & & & & & & & & $2=1$ & \\
\hline & 22,0 & $\cdots$ & $\cdots$ & 3,54 & 0,21 & 0,54 & 0,50 & 0,54 & 0,30 & 1,84 & 3,91 & 13,45 \\
\hline & 22,0 & $\cdots$ & $\cdots$ & 4,70 & 0,10 & 1,00 & 0,80 & 0,80 & 0,51 & 1,76 & 4,01 & 17,52 \\
\hline & 22,0 & $\cdots$ & $\cdots$ & 11,98 & 0,51 & 2,14 & 2,45 & 0,99 & $-0,41$ & 0,58 & 4,29 & 39,45 \\
\hline & 22,0 & $\cdots$ & 7,0 & 11,89 & 0,06 & 0,92 & 0,25 & 1,29 & 0,66 & 1,78 & 3,96 & 45,54 \\
\hline & 22,0 & 34,0 & 8,0 & 17,35 & 0,14 & 2,27 & 3,05 & 1,21 & $-0,78$ & 0,55 & 4,38 & 55,47 \\
\hline & 22,0 & 33,0 & 8,0 & 19,86 & 0,02 & 3,25 & 3,25 & 0,24 & $-0,13$ & 1,56 & 4,65 & 57,45 \\
\hline & 22,0 & 32,0 & 8,0 & 19,76 & 0,09 & 3,28 & 3,30 & 0,21 & $-0,13$ & 1,31 & 5,30 & 44,30 \\
\hline & 22,0 & 33,0 & 8,0 & 19,45 & 0,14 & 3,27 & 3,25 & 0,28 & $-0,08$ & 1,50 & 4,74 & 53,94 \\
\hline 24 & 22,0 & 30,0 & 8,0 & 19,96 & - & 3,27 & 3,30 & 0,67 & $-0,49$ & 4,22 & 5,14 & 47,44 \\
\hline \multirow{7}{*}{ 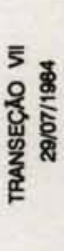 } & 20,0 & $\cdots$ & 7,0 & 5,12 & $\ldots$ & 1,48 & 1,25 & 0,88 & 0,37 & 0,82 & 3,99 & 19,60 \\
\hline & 20,0 & $\cdots$ & 8,0 & 11,72 & 0,58 & 2,17 & 2,40 & 0,93 & $-0,31$ & 0,76 & 4,62 & 34,40 \\
\hline & 21,0 & $\cdots$ & 8,0 & 12,54 & 0,47 & 1,15 & 0,40 & 1,32 & 0,66 & 0,62 & 3,99 & 47,99 \\
\hline & 21,0 & 32,0 & 8,0 & 18,07 & 0,38 & 2,15 & 2,80 & 1,26 & $-0,63$ & 0,52 & 4,71 & 51,23 \\
\hline & 21,5 & 33,0 & 8,0 & 19,25 & 0,18 & 3,24 & 3,25 & 0,26 & $-0,19$ & 1,56 & 4,79 & 52,73 \\
\hline & 21,5 & 29,0 & 8,0 & 19,49 & 0,17 & 3,25 & 3,25 & 0,25 & $-0,15$ & 1,37 & 4,71 & 55,37 \\
\hline & 21,5 & 31,0 & 8,0 & 21,43 & 0,20 & 3,27 & 3,25 & 0,27 & $-0,06$ & 1,43 & 4,89 & 56,62 \\
\hline 21 & 22,0 & 27,0 & 8,0 & 19,44 & 0,14 & 3,28 & 3,30 & 0,40 & $-0,37$ & 2,60 & 5,02 & 48,62 \\
\hline \multirow{12}{*}{ 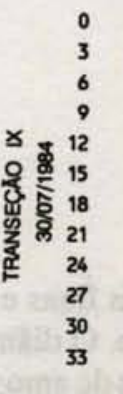 } & 20,0 & $\cdots$ & 7,0 & 9,04 & 0,87 & 1,64 & 1,85 & 1,40 & $-0,20$ & 0,56 & 3,70 & 38,98 \\
\hline & 21,5 & $\cdots$ & 6,0 & 8,18 & 1,16 & 1,05 & 0,45 & 1,54 & 0,43 & 0,61 & 3,63 & 36,26 \\
\hline & 22,0 & $\cdots$ & 6,0 & 9,99 & 1,08 & 1,28 & 0,85 & 1,45 & 0,32 & 0,59 & 4,14 & 35,91 \\
\hline & 22,0 & $\cdots$ & 6,0 & 9,82 & 0,95 & 1,14 & 0,45 & 1,51 & 0,51 & 0,58 & 3,73 & 41,42 \\
\hline & 22,0 & $\cdots$ & 7,0 & 9,84 & 0,85 & 1,08 & 0,40 & 1,52 & 0,53 & 0,54 & 3,47 & 46,61 \\
\hline & 22,0 & $\cdots$ & 7,0 & 10,84 & 0,35 & 1,12 & 0,70 & 1,61 & 0,28 & 0,60 & 3,64 & 48,16 \\
\hline & 22,0 & 30,0 & 7,0 & 10,84 & 0,94 & 0,64 & $-0,10$ & 1,69 & 0,54 & 0,81 & 3.76 & 45,30 \\
\hline & 22,0 & 30,0 & 8,0 & 13,52 & 0,81 & 0,70 & $\cdot$ & 1,64 & 0,52 & 1,44 & 3,60 & 60,55 \\
\hline & 21,5 & 25,0 & 7,0 & 14,54 & 0,49 & 1,02 & 0,30 & 1,67 & 0,49 & 0,55 & 3,58 & 65,61 \\
\hline & 21,0 & 31,0 & 7,0 & 23,14 & 0,69 & 1,10 & 0,45 & 1,63 & 0,42 & 0,56 & 4,16 & 81,02 \\
\hline & 21,0 & 27,0 & 7,0 & 17,71 & 0,44 & 2,15 & 3,10 & 1,62 & $-0,76$ & 0,59 & 3,91 & 69,81 \\
\hline & 21,0 & 32,0 & 7,0 & 14,87 & 0,89 & 1,12 & 0,40 & 1,63 & 0,48 & 0,56 & 3,66 & 65,10 \\
\hline
\end{tabular}

T I: 18:00-20:50 h. Marés previstas: $15: 53 \mathrm{~h}-1,0 \mathrm{~m} ; 21: 01 \mathrm{~h}--0,1 \mathrm{~m}$. Sentido da coleta: $0-53 \mathrm{~m}$.

T III: 20:40-20:55 h. Marés previstas: $15: 03 \mathrm{~h}-1,1 \mathrm{~m} ; 21: 45 \mathrm{~h}--0,2 \mathrm{~m}$. Sentido da coleta: $33-0 \mathrm{~m}$.

T V: 12:05-12:45 h. Marés previstas: $10: 50 \mathrm{~h}-0,4 \mathrm{~m} ; 15: 19 \mathrm{~h}-1,2 \mathrm{~m}$. Sentido da coleta: $24-0 \mathrm{~m}$.

T V/7: 08:23-08:55 h. Marés previstas: 02:33 h-1.0 m; 08:54 h- $0,0 \mathrm{~m}$. Sentido da coleta: 24 - $0 \mathrm{~m}$.

T VI: 08:55-09:36 h. Marés previstas: 02:53 h-1,1 m; 09:39 h- 0,0 m. Sentido da coleta: $0-21 \mathrm{~m}$.

T IX: 10:15-11:10 h. Marés previstas: 10:23 h-0,0 m; 15:45 h - 1,2 m. Sentido da coleta: $33-0 \mathrm{~m}$.

Legenda:

Diâmetro médio: Arela grossa ( $\varnothing$ 0-1,0); Areia média $(\varnothing 1,01-2,0)$; Arela fina $(\varnothing 2,01-3,0)$; Areia multo fina $(\varnothing 3,01-4,0)$.

Grau de seleçao: Multo bem selecionado $(<0,35)$; Bem selecionado $(0,35-0,50)$; Moderadamente selecionado $(0,50-1,0)$; Pobremente selecionado $(1,0-2,0)$; Muto pobremente selecionado $(2,0-4,0)$; Extremamente mal selecionado $(>4,0)$

Grau de assimetria: Assimetria multo negativa (entre $-1,00$ e $-0,30$ ); Assimetria negativa (entre $-0,30$ e $-0,10$ ); Aproximadamente simétrica (entre - 0,10 e +0,10): Assimetria positiva (entre $+0,10$ e $+0,30$ ): Assimetria multo positiva (entre $+0,30$ e $+1,00$ ).

Curtose: $\quad$ Multo platicúrtica $(<0,67)$; Paticúrtica $(0,67-0,90)$; Mesocúrtica $(0,90-1,11)$; Leptocúrtica $(1,11-1,50)$; Muito leptocúrtica $(1,50-3,00)$; Extremamente leptocúrtica $(>3,00)$. 


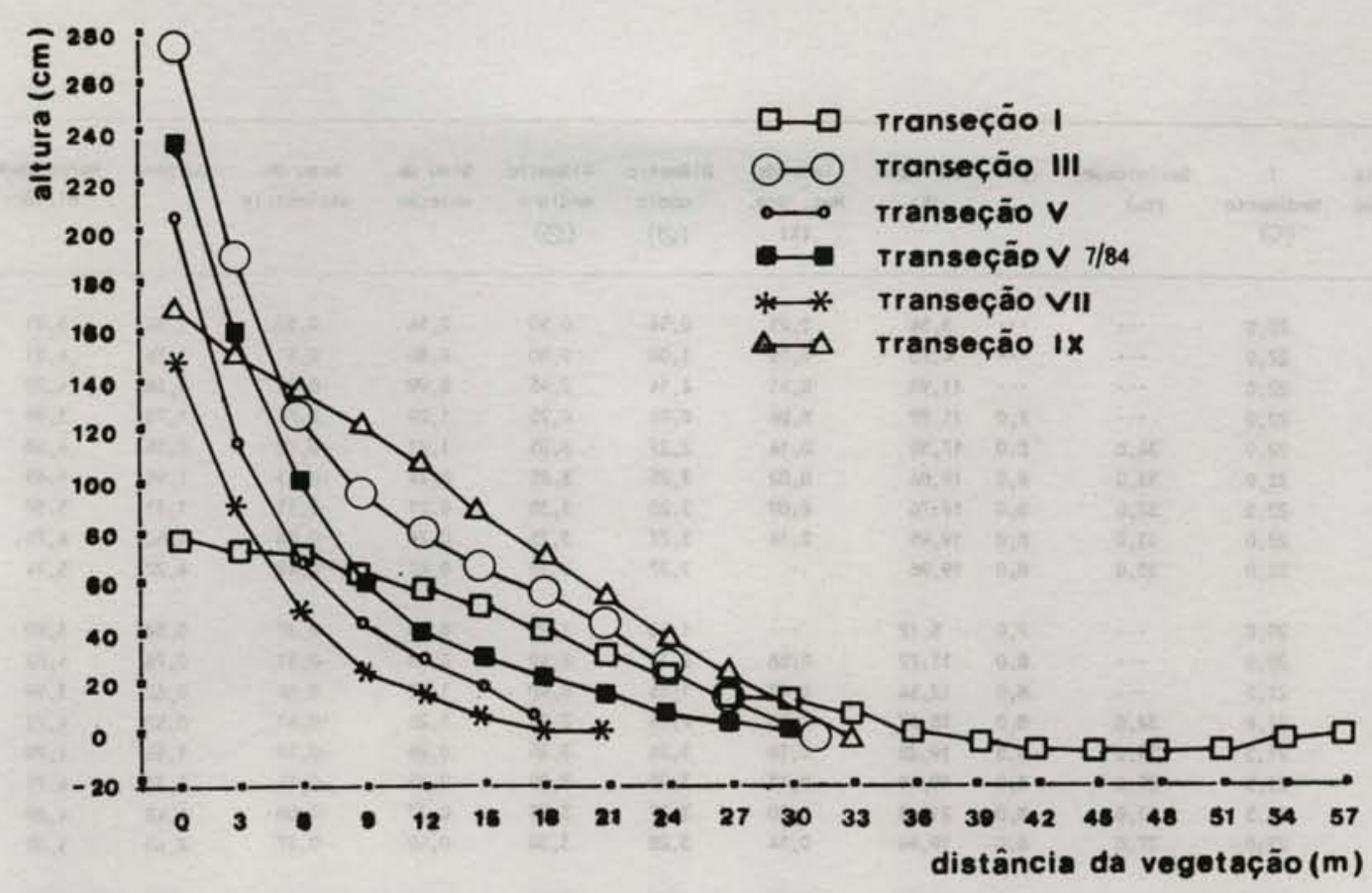

Fig. 3. Ilha Anchieta, Praia Grande: diagrama de perfis.

As areias muito finas, que ocorreram principalmente próximas à linha d'água, foram geralmente muito bem selecionadas e aproximadamente simétricas. Assim, os valores obtidos para diâmetros médios e medianos (Tab. 1) sāo muito próximos, quando nāo iguais. $O$ diâmetro dos poros foi de 55,54-77,36 $\mu \mathrm{m}$ ( 27 unidades de amostra).

Areias finas foram, em geral, pobremente selecionadas e de assimetria muito negativa (média menor que a mediana e distribuição desviada para as partículas grosseiras). Em T I tenderam a ser mesocúrticas, leptocurticas, ou extremamente leptocúrticas. Areias leptocúrticas indicam um sedimento relativamente bem selecionado na parte central da distribuiçāo. Nas demais transeçöes, as areias finas foram platicúrticas ou muito platicurticas, o que indica distribuiçōes bimodais. Nestas areias, o diâmetro dos poros foi de 103,38-127,46 $\mu \mathrm{m}$ (3 unidades de amostra).

As areias médias foram também pobremente selecionadas, e as assimetrias foram geralmente muito positivas, indicando que a distribuição se acha desviada para as partículas mais finas. As distribuiçôes das areias médias foram também bimodais. O diâmetro dos poros avaliado para uma unidade de amostra com coeficiente de seleção próximo a 1 , foi de $158,87 \mu \mathrm{m}$.

O grau de seleção das areias grossas foi bastante variado, com pontos de grão bem selecionado (1 ponto), moderadamente selecionado (4) e pobremente selecionado (4). Os valores de distribuição encontram-se geralmente desviados para as partículas mais finas e bem selecionados na parte central da distribuição. $O$ diâmetro dos poros foi de $222,87-332,36 \mu \mathrm{m}$ ( 5 unidades de amostra).

Aos pontos de maior declividade associaram-se areias grossa e média; aos de menor, areias fina e muito fina.

Tomando por base o sistema de classificaçāo de praias de Short \& Wright (1983; v. também Short, 1983, 1984), morfodinâmico de curto termo (Chapman, 1983), a Praia Grande parece aproximar-se de um tipo intermediário de baixa energia, tendendo a refletivo. As variaçōes ao longo da praia, contudo, mostram TI, a leste, com características de estado dissipativo (sedimento fino, perfil plano, larga) e T IX, a oeste, com fisionomia refletiva (sedimento grosso, gradiente acentuado, degrau de areia grossa próximo ao N.B.M., camada delgada de sedimentos finos resultantes de transporte é́lico recobrindo as porçōes mais próximas à vegetação). Essas variaçōes longitudinais sugerem um gradiente decrescente de energia, de leste para oeste, resultante de uma atenuação progressiva das ondas refratadas provenientes de leste durante o seu percurso sobre fundos rasos. $\mathrm{O}$ estado dissipativo a leste poderia decorrer de modificaçōes hidrodinâmicas locais, talvez de correntes oriundas da convergência da energia das ondas na ponta rochosa que aí se encontra já que as ondas na regiāo sāo, como regra, baixas. Tal estado no extremo leste da praia não deve ser acidental, já que em todas as visitas efetuadas à regiāo (janeiro, julho, setembro e dezembro de 1981 , setembro de 1983, fevereiro e julho de 1984, outubro 
de 1990) observou-se, ar, o perfil de menor gradiente e a granulação mais fina.

Com relação à energia hidrodinâmica perpendicularmente à linha d'água, esta é a maior, nos estados refletivos, no degrau (N.B.M.) de areia grossa, mas está, toda a faixa, sob o domínio refletivo, de baixa energia. Nos estados intermediários, a profundidade do distúrbio aumenta entre a crista da praia e a plataforma costeira (domínio dissipativo), estando o restante (porçōes mais superiores) sob o domínio refletivo. Nos estados dissipativos, a energia $e$ alta sobre toda praia (domínio dissipativo), a erosão maior ocorrendo na regiâo das antedunas e, na parte baixa da praia, as correntes de retorno têm alta velocidade (Short \& Wright, 1983; Short, 1983).

Na Praia Grande, a fauna estaria, então, sujeita a um hidrodinamismo mais intenso (domínio dissipativo) em toda $\mathrm{T}$ I e porção inferior da praia (sedimento fino) das transeçōes III-VII, mas sujeita a um hidrodinamismo brando (domínio refletivo) na alta-praia de T III a T VII e por toda T IX.

Resultados faunísticos (Medeiros, 1987, 1989) concordam com essa "distribuiçāo" atual de energia hidrodinâmica perpendicularmente à linha d'água. Batillipedidae (Tardigrada), grupo de locais abrigados (Grimaldi de Zio et al., 1983), abundou nos sedimentos mais grosseiros do domínio refletivo. Depressōes na abundância faunística, ocorrentes sob hidrodinamismo acentuado (Hulings \& Gray, 1976), verificaram-se no domínio dissipativo.

A seleção dos sedimentos é melhor onde ocorre a açāo de ondas, marés e correntes e pior onde a açāo desses fatores é fraca (Eleftheriou \& Nicholson, 1975; Hulings \& Gray, 1976). Relações positivas entre sedimentos bem selecionados e hidrodinamismo mais severo e entre sedimentos de seleção pobre e hidrodinamismo brando parecem pertinentes para a Praia Grande.

\section{Teor de água, porosidade e porcentagem de saturação}

Os valores de teor de água do sedimento tenderam a aumentar com a proximidade da linha d'água e com o decréscimo do tamanho do grão (Tab. 1). Excetuando-se T I, os teores de água nos pontos mais próximos à vegetação $(0-6 \mathrm{~m})$ foram maiores no inverno do que no verāo, quando as diferenças nos teores de água entre pontos próximos e distantes da vegetação foram mais acentuadas. O valor $50,44 \%$ obtido em T I é aberrante.

A porosidade apresentou uma ligeira tendência ao aumento na metade inferior da praia (Tab. 1). Este resultado está coerente com as características granulométricas gerais e influencia a mesma tendência no teor de água.

A transeção IX, constituída quase que totalmente por sedimento mais grosso, apresentou, em média, a menor porosidade. Ao contrário, T I, com pequena declividade e sedimento fino mesmo nos pontos mais distantes da linha d’água, teve valores de porosidade e teores de água relativamente altos até nesses pontos.

Excetuando-se T I, o sedimento tendeu, de um modo geral, a se apresentar progressivamente mais saturado com a proximidade marinha (Tab. 1).

A transeção I apresentou-se bastante saturada mesmo nos pontos mais distantes da linha d'água. Nesse setor, a praia apresenta-se constituída por sedimentos finos, de alta capacidade de retenção de água, e a declividade, suave, deve permitir, mormente nos perfodos de grande amplitude de maré, inundações até as proximidades do limite terrestre.

Os pontos mais próximos aos limites terrestres apresentaram-se, de um modo geral e excetuando-se novamente T I, mais saturados no inverno do que no verão. Tais pontos estiveram sujeitos a aquecimento e, provavelmente, evaporação, menores no inverno do que no verāo.

Ocorreu, com freqüência, que pontos próximos à linha d'água estivessem algo mais saturados do que o ponto mais próximo desta. Podem ter ocorrido estratificações verticais do sedimento não medidas que, modificando a capacidade de retenção, respondam por esse resultado. Ainda, condições microtopográficas, como as obtidas em T I, podem ter determinado esse resultado, com acúmulo de água nas depressōes e escoamento nas elevações. Valores aberrantes de saturação foram obtidos em T I 24 me T III $27 \mathrm{~m}$. No primeiro caso pode ter ocorrido, durante a coleta, uma "invasão" de água intersticial, tendo-se, aqui, uma mistura fluída de muita água com pouca areia. Pode, ainda, ter ocorrido algum acidente durante o processamento para teor de água, com perda de sedimento após evaporada grande parte da água. Em T III 27 m, a amostra possivelmente entornou antes de sua primeira pesagem.

\section{Temperatura}

No verão, diferenças de temperatura (Tab. 1) entre períodos diurno e noturno foram leves nos pontos próximos à linha d'água e acentuadas naqueles emersos por períodos de tempo mais prolongados. Nesse período, as temperaturas do sedimento decresceram em direçāo ao mar, obtendo-se tendência oposta em T VII (inverno). T IX apresentou temperaturas mais elevadas em sua porção central e T V 7/84 teve os mesmos valores em todos os pontos.

Quanto às gradaçōes de temperatura perpendiculares à linha d'água, a praia foi mais homogênea no inverno (amplitude máxima por transeção de $2^{\circ} \mathrm{C}$ ), quando só se fez observaçōes diurnas, do que no verão (amplitude máxima de $8^{\circ} \mathrm{C}$ ).

As características climáticas da região condicionam a ocorrência de temperaturas muito altas na superfície do sedimento das porçōes superiores da praia. 
Embora as flutuaçōes de temperatura tendam a decrescer com a profundidade no sedimento (Jansson, 1967; Wieser, 1975), naqueles mais grossos de áreas expostas, a flutuação térmica é transmitida rapidamente para camadas mais profundas que podem, entảo, apresentar temperaturas próximas às de superfície (Wilson, 1983).

Como, na Praia Grande, sedimentos mais grossos parecem nāo se associar a uma maior energia hidrodinâmica, é possível que, nas porçōes superiores da praia, o regime térmico dos estratos profundos seja mais constante, diverso daquele dos estratos superficiais.

\section{Salinidade}

O sedimento das partes mais próximas à vegetação é, muitas vezes, pobre em água intersticial na profundidade amostrada, o que impossibilitou, á, medidas de salinidade e $\mathrm{pH}$.

Em T I, a salinidade (Tab. 1), decrescente em direção à alta-praia, apresentou a maior amplitude $(30 \%)$, valor inferior a $20 \%$ só ocorreu em um ponto ( $\mathrm{T} \mathrm{V}, 18 \mathrm{~m}$ ) das demais transeçōes.

Foi razoavelmente comum, na porção inferior da praia, a ocorrência de pontos com salinidade marcadamente mais baixa entre pontos com valores próximos à salinidade marinha. As chuvas registradas pareceram nảo influir nos valores de salinidade.

A salinidade tendeu a distribuir-se conforme o padrāo mais comum, (Jansson, 1971; Pollock, 1971; Medeiros, 1990), com valores altos nas proximidades da linha d'água: aqui, os eventuais decréscimos (T I) devem, provavelmente, ser atribuídos à ressurgência do lençol freático.

\section{pH e matéria orgânica}

Nảo se distanciando muito do neutro, os valores de $\mathrm{pH}$ (Tab. 1) mostraram maior amplitude em T I e T IX, sendo muito homogêneos em T V 7/84 e T VII. Valores mais baixos por vezes associaram-se à alta-praia, nāo havendo, contudo, tendência nítida de incremento com a proximidade da linha d'água.

Valores de $\mathrm{pH}$ um pouco mais baixos do que os menores normalmente referidos (6,9: Wieser, 1975; Gnaiger et al., 1978) foram registrados, mas o método aqui utilizado nāo oferece muita precisāo. Os valores mais baixos das porçōes superiores da praia parecem confirmar a maior acidez da água intersticial, se comparada à marinha (Pollock, op. cit.): nas porçōes mais baixas, freqüentemente alcançadas pela água do mar, não deve haver diferenças acentuadas entre a água do mar e a intersticial.
Estimativas de conteúdo orgânico por perdas em ignição sāo consideradas satisfatórias em sedimentos não argilosos (Páez-Ozuna et al., 1984), mas durante o processo de extraçāo da fauna por decantaçāo e lavagens, que precedeu as medidas de teor de matéria orgânica, grande parte do material orgânico particulado foi também extraída. Assim, os valores de matéria orgânica aqui obtidos subestimam os teores reais: permitem, grosseiramente, uma comparação entre as amostras, porém nâo são perfeitamente comparáveis com os dados da literatura.

Os teores de matéria orgânica (Tab. 1) foram expressivamente mais altos em T VII e T IX. Na amostragem de julho, houve uma ligeira tendência à diminuição nos teores de matéria orgânica com a proximidade da linha d'água. Mais altos na pós-praia e em T IX, os teores de matéria orgânica relacionaram-se inversamente ao $\mathrm{pH}$, cujos valores explicam parcialmente.

Teores de matéria orgânica baixos, inferiores a $0,70 \%$, concomitantes à ocorrência de areia muito fina, foram registrados na Praia Grande por Amaral (1979). No presente trabalho, os teores de matéria orgânica obtidos foram também baixos, principalmente nos sedimentos muito fino, fino e grosso (aqui, é provável que grande parte percole até camadas mais profundas). Nas areias médias obteve-se valores relativamente mais altos, mas, ainda assim, baixos. Deve-se, contudo, considerar as restriçōes da metodologia empregada na análise deste fator, que impedem uma comparaçāo precisa.

O hidrodinamismo mais suave do domínio refletivo possivelmente favorece a residência da matéria orgânica. Quando tal domínio é alcançado pelas ondas e marés, parte da matéria orgânica pode ser carreada para o mar, mas parte percola o sedimento, provavelmente bastante permeável, acumulando-se em camadas mais profundas. Na Praia Grande, ao lado de uma fonte marinha de matéria orgânica, circunstanciada pela presença de fragmentos de algas (principalmente Sargassum sp), há uma fonte terrestre, indiciada por fragmentos de folhas e ramos caulinares de fanerógamas.

\section{Considerações finais}

A Praia Grande poderia ter, atualmente, duas fontes de sedimentos: (a) o mar, fornecendo sedimentos finos, retrabalhados, bem selecionados e (b) a drenagem, suprindo-a de sedimentos grossos imaturos. Na Praia Grande, os sedimentos grossos, acumulados preferencialmente nas proximidades da desembocadura do rio, seriam redistribuídos mediante transporte de oeste para leste.

Uma outra hipótese, baseada sobretudo nos trabalhos de plataforma continental de Dias \& Neal (1990), relacionaria as características sedimentares da Praia Grande às flutuaçōes do nível relativo do mar. Conforme os princípios estabelecidos por esses autores para modas granulométricas, sedimentos em equilíbrio com as 
condições hidrodinâmicas tendem à unimodalidade, característica apresentada pelas areias muito finas da Praia Grande. Já a polimodalidade, ocorrente em areias média-grossa da Praia Grande (v. também Medeiros, 1989, Tab. XVI), geralmente existe onde há uma mudança acentuada seja no nível de energia do fundo, seja nas fontes de sedimento e/ou características de tamanho de partículas disponíveis para sedimentação. Assim, a polimodalidade relaciona-se ao tempo, podendo-se distinguir modas de sedimento "relicto" ou "moderno", cujo tempo que as separa, altamente variável, vai de dias a milhōes de anos (Dias \& Neal, op. cit.). A persistência da primeira nos depósitos é função da intensidade e tempo de atuaçāo quer dos processos distribuidores operantes, quer dos processos supridores.

Modas "relicto" mais grossas, que podem formar-se durante os raros períodos de alta energia, têm maior probabilidade de permanecer do que as modas relictuais finas, que podem ser removidas durante esses períodos. Modas relictuais grossas bem desenvolvidas, se presentes, podem indicar que o "nível atual de energia próximo ao fundo é baixo e/ou há inadequado suprimento de sedimento e/ou partículas fornecidas no presente desviam-se da zona" (Dias \& Neal, op. cit., p. 429).

Apesar da constataçāo de épocas de nfveis marinhos mais altos do que o atual no Holoceno (ca. 5100 anos A.P.), seguida de tendência de abaixamento nos últimos milênios, pode-se até admitir a subida do nivel relativo do mar nas últimas dezenas de anos neste trecho da costa brasileira, possivelmente por causas tectônicas (Fulfaro et al., 1974; Suguio \& Martin, 1987).

Perturbação do perfil de equilíbrio na zona litorânea, ocasionando a erosão da pós-praia com transferência e deposição do material erodido na antepraia, ocorre em períodos de tempestade, marés de sizígia ou elevação do nivel do mar, todos constituindo, por assim dizer, "períodos transgressivos". O processo inverso, ou seja, erosão na antepraia e deposição na pós-praia, ocorre nos "períodos regressivos" durante marés de quadratura ou de abaixamento do nível do mar (Martin et al., 1987).

Assim, na Praia Grande, os sedimentos mais grossos da alta-praia seriam em grande parte relictuais depositados neste último episódio de abaixamento do nível relativo do mar. $\mathrm{Na}$ transgressāo das últimas décadas (Mesquita \& Leite, 1986), as partículas finas estāo sendo depositadas. Desenvolvem subpopulações que acabam por constituir, inicialmente, uma moda secundária (situação atual nos sedimentos de maior diâmetro médio). Esta moda aumenta progressivamente até tornar-se a moda principal (Dias \& Neal, op. cit.), situação atual nos sedimentos de menor diâmetro médio.

Deste modo, o extremo leste da Praia Grande aproximar-se-ia de um "estágio final", onde o sedimento ajusta-se às condiçōes atualmente operantes. No extremo oeste, subpopulações relictuais conservar-se-iam, formando as modas grossas bem desenvolvidas. A defasagem no processo de erosão de relictos, soterramento e diluiçāo por finos apresentada na extensāo leste-oeste da praia poderia relacionar-se a um nível de energia hidrodinâmica decrescente para oeste da praia, com inadequado fornecimento de finos e/ou desvio das partículas.

Um exame morfosc6́pico preliminar, sob lupa binocular, em algumas amostras, revelou a presença de caracteres relictuais nas modas mais grossas (Dias \& Neal, op. cit.). Comparadas às mais finas, estas modas apresentaram maior porcentagem de partículas subarredondadas a bem arredondadas e mostraram manchas ferruginosas; os fragmentos de conchas, geralmente acastanhados e bem redondos, tinham aparência antiga, com superfície desgastada, sem ornamentaçāo e camada nacarada evidentes.

Bom arredondamento $e$ indicativo de maior grau de maturidade (Suguio, 1980) e de "antiguidade" (Dias \& Neal, op. cit.), mas associado a outras características, ocorre também onde haja pequeno transporte e retrabalhamento (Cruz et al., 1985). Minerais de ferro nāo são apenas uma característica de sedimento "relicto" (Dias \& Neal, op. cit.); aqui, podem atestar sua origem a partir das rochas cristalinas regionais (Fulfaro et al., 1974; Eichler, 1982). De qualquer modo, a plausibilidade das hipóteses aqui apresentadas, que não são necessariamente exclusivas, ou de outras hipoteses, s6 seria abalizada mediante observaçōes e estudos adicionais.

A praia estudada pode ser dividida em dois subsistemas (Fig. 4), um correspondendo ao domínio refletivo e outro ao dissipativo (Short \& Wright, 1983; Short 1983, 1984). O limite entre esses dois dominios não deve ser fixo, posto que as condiçōes morfodinâmicas da praia variam em função de períodos mais dissipativos ou mais refletivos.

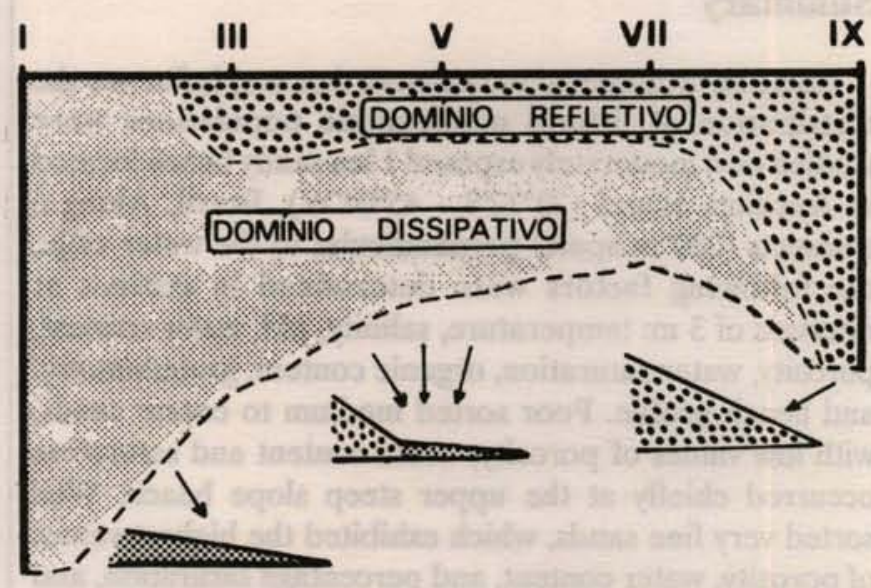

Fig. 4. Prala Grande. Esquema de repartiçăo dos domínios refletivo e dissipativo e perfil generallzado nas transecçőes $I, V$ $~ I X$.

O domínio refletivo, sob hidrodinamismo leve, caracteriza-se por apresentar, geralmente, areias média a grossa, que podem ser, em parte, relictuais. Tais sedimentos, de baixa porosidade e prevalecentes na alta-praia, tendem a permanecer com baixa saturação de 
água e estão sujeitos a temperaturas extremas. Contudo, saturação elevada e temperaturas sempre amenas ocorrem quando próximos ao mar. Os teores de matéria orgânica são mais altos do que no domínio dissipativo, e os teores de oxigênio devem ser comparativamente altos mesmo nos estratos mais profundos. $\mathrm{O}$ diâmetro dos poros é amplo, possibilitando a existência de uma fauna intersticial abundante que ocupa, preferencialmente, estratos mais profundos do sedimento (Medeiros, 1987, 1989). Neste domínio, de maior estabilidade relativa, a fauna intersticial deve apresentar-se mais "isolada", só alcançando massivamente a água do mar quando, por modificações nos níveis de energia, sobrevêm condiçōes de erosāo mais intensa, aproximando as feiçōes praiais daquelas do estado dissipativo.

O domínio dissipativo nāo teve, no presente trabalho, seu limite marinho estabelecido. Caracteriza-se por apresentar, geralmente, sedimentos muito finos, muito bem selecionados, sob um hidrodinamismo mais intenso. O sedimento, de alta porosidade, tende a permanecer saturado, e temperaturas extremas sảo experimentadas geralmente $s 6 \mathrm{em}$ pontos afastados do mar. Os teores de matéria orgânica são muito baixos, e os de oxigênio são provavelmente baixos nos estratos mais profundos, mas depleção de oxigênio pode ocorrer no estrato superficial superaquecido. O diâmetro dos poros, pequeno (Medeiros, 1989), nāo oferece habitat adequado à vida intersticial. O hidrodinamismo mais intenso deve facilitar a suspensão dos organismos na coluna d'água, tornando-os sujeitos a um maior intercâmbio com outras localidades.

\section{Summary}

Some environmental parameters that may influence the distribution of littoral meiobenthic populations were studied on a moderately exposed $1 \mathrm{~km}$ sandy beach located at Anchieta Island ( $\left.23^{\circ} 32^{\prime} \mathrm{S}-4^{\circ} 04^{\prime} \mathrm{W}\right)$, Brazil. Along 5 transects ( $200 \mathrm{~m}$ apart) perpendicular to the water edge, the following factors were determined in stations at intervals of $3 \mathrm{~m}$ : temperature, salinity, $\mathrm{pH}$, water content, porosity, water saturation, organic content, granulometry, and beach profile. Poor sorted medium to coarse sands, with low values of porosity, water content and saturation occurred chiefly at the upper steep slope beach. Well sorted very fine sands, which exhibited the highest values of porosity, water content, and percentage saturation, and lower organic content lay at the lower gentle slope beach. Reflective and dissipative domains could be recognized. The former consists of coarser sands that can partially be relictual, and offers pore spaces suitable to interstitial life. Probably it can display higher stability due to slight hydrodynamic forces, and is more isolated from the adjacent marine system. Its temperatures may reach high values in the upper sediment layer. The dissipative domain, here only partially sampled, has very fine well sorted sands submitted to more vigorous hydrodynamic forces. Its temperature tends to show less extreme and more uniform values.

\section{Resumo}

Parâmetros ambientais que influenciam a distribuiçāo de populaçōes do meiobentos litorâneo foram estudados em uma praia arenosa moderadamente exposta, localizada na Ilha Anchieta ( $\left.23^{\circ} 32^{\prime} \mathrm{S}-45^{\circ} 04^{\prime} \mathrm{W}\right)$, Brasil. Areias média a grossa, probremente selecionadas, com valores baixos de porosidade, teor de água e saturação ocorreram principalmente na porção superior da praia, de declive acentuado. Areias muito finas, bem selecionadas, com os mais altos valores de porosidade, teor de água e saturaçāo, e menor teor de matéria orgânica, estiveram na porção inferior da praia, de declive suave. Os domínios refletivo e dissipativo puderam ser reconhecidos. No primeiro os sedimentos, mais grosseiros, podem ser, em parte, relictuais; os poros, mais amplos, sāo adequados à vida intersticial; o hidrodinamismo, mais brando, provavelmente condiciona maior estabilidade relativa e maior isolamento do sistema marinho adjacente. Neste domínio, as temperaturas do estrato superficial do sedimento podem alcançar valores altos. O domínio dissipativo, aqui s6 parcialmente amostrado, tem areias finas bem selecionadas sujeitas a forças hidrodinâmicas mais vigorosas; as temperaturas tendem a apresentar valores menos extremos e mais uniformes.

\section{Agradecimentos}

À Profa. Dra. Liliana Forneris (IB-USP), que orientou este estudo. Ao Prof. Dr. Kenitiro Suguio (IG-USP), pela leitura do manuscrito e sugestōes. A Sra. Herminia Bernardi, pela digitação do manuscrito. Ao Sr. Levi Ciobotariu, pelas ilustraçōes. A dois Assessores anônimos deste Boletim, pelas críticas e sugestōes. Aos amigos que auxiliaram em várias etapas. Este trabalho é parte de uma dissertação de mestrado subvencionada por bolsa da CAPES.

\section{Referências bibliograficas}

AB'SÁBER, A. N. 1970. Províncias geologicas e domínios morfoclimáticos no Brasil. Geomorfologia, Inst. Geogr. Univ. S Paulo, 20:1-26.

AMARAL, A. C. Z. 1979. Ecologia e contribuição dos anelídeos poliquetos para a biomassa bêntica da zona das marés, no litoral norte do Estado de São Paulo. Bolm Inst. oceanogr., S Paulo, 28(1):1-52.

1980. Anelídeos poliquetos do infralitoral em duas enseadas da região de Ubatuba. I. Características abíticas das enseadas. Bolm Inst. oceanogr., S Paulo, 29(1):19-40. 
AMOUREUX, L. 1966. Etude bionomique et écologique de quelques annélides polychétes des sables intertidaux des côtes Ouest de la France. Archs Zool. exp. gen., 1(1):1-218.

CASTRO FILHO, B. M.; MIRANDA, L. B. de \& MTYAO, S. Y. 1987. Condiçōes hidrográficas na plataforma continental ao largo de Ubatuba: variaçōes sazonais e em média escala. Bolm Inst. oceanogr., S Paulo, 35(2):135-151.

CHAPMAN, D. M. 1983. Sediment reworking on sandy beaches. In: McLachlan, A. \& Erasmus, T., eds. Sandy beaches as ecosystems. The Hague, Dr. W. Junk. p. 45-60.

CRISP, D. J. \& WILlIAMS, R. 1971. Direct measurement of pore size-distribution in artificial and natural deposits and predictions of pore space accessible to interstitial organisms. Mar. Biol., 10:214-226.

CRUZ, O. 1974. A serra do Mar e o litoral, na área de Caraguatatuba. Sér. Teses Monogr., Inst. Geogr. Univ. S Paulo, (11):1-181.

; SU'GUIO, K. \& EICHLER, B. B. 1985. Sedimentação acelerada de pontais e barras arenosas na enseada de Caraguatatuba, SP: causas naturais e artificiais. Bolm Inst. oceanogr., S Paulo, 33(1):39-53.

DIAS, J. M. A. \& NEAL, W. J. 1990. Modal size classification of sands: an example from the northern Portugal continental shelf. J. sedim. Petrology, 60(3):426-437.

EICHLER, B. B. 1982. Caracterização sedimentologica e algumas consideraçōes sobre a ocorrência de foraminiferos na Enseada do Flamengo (Ubatuba). Tese de doutorado. Universidade de São Paulo, Instituto Oceanografico. 109 p.

ELEFTHERIOU, A. \& NICHOLSON, M.D. 1975. The effects of exposure on beach fauna. Cah. Biol. mar., 16(5):695-710.

FOLK, R. L. \& WARD, W. C. 1957. Brazos river bar: a study in the significance of grain size parameters. J. sedim. Petrology, 27(1):3-26.

FORNERIS, L. 1969. Fauna do sublitoral da Itha Anchieta $\left(23^{\circ} 32^{\prime} \mathrm{S}-45^{\circ} 04^{\prime} \mathrm{W}\right)$. Ciênc. Cult., S Paulo, 21(2):449-450.

FULFARO, V. J.; SUGUIO, K. \& PONÇANO, W. L. 1974. A gênese das planícies costeiras paulistas. In: CONGRESSO BRASILEIRO DE GEOLOGIA, 28., Porto Alegre, 1974. Anais. Porto Alegre, Sociedade Brasileira 'de Geologia. v. 3, p.37-42.
FUMEST, São Paulo. 1974. Iltha Anchieta: plano geral de exploração turística. São Paulo, Secretaria de Esportes e Turismo. 69 p. (divulgação restrita).

GIERE, O.; ELEFTHERIOU, A. \& MURISON, D.J. 1988. Abiotic factors. In: Higgins, R. P. \& Thiel, H., eds. Introduction to the study of meiofauna. Washington, D.C., Smithsonian Institution Press. p. 61-78.

GNAIGER, E.; GLUTH, G. \& WIESER, W. 1978. $\mathrm{pH}$ flutuaction in an intertidal beach in Bermuda. Limnol. Oceanogr., 23(5):851- 857.

GRIMALDI de ZIO, S.; LUCIA, R. M. de \& D'ADDABBO GALLO, M. 1983. Marine tardigrades ecology. Oebalia, n.s., 9:15-31.

HULINGS, N. C. \& GRAY, J. S. eds. 1971. A manual for the study of meiofauna. Smithson. Contr. Zool., (78):1-84.

$\&$ 1976. Physical factors controlling abundance of meiofauna on tidal and atidal beaches. Mar. Biol., 34(1):77-83.

JANSSON, B.-O. 1967. Diurnal and annual variations of temperature and salinity of interstitial water in sandy beaches. Ophelia, 4(2):173-201.

1971. The "umwelt" of the interstitial fauna. Smithson. Contr. Zool., 76:129-140.

MALDONADO, S. R. C.; ISHIHATA, L. \& POLETTE, M. 1987. Proposta para planejamento a partir da caracterização do litoral de Ubatuba - SP. In: SIMPÓSIO SOBRE ECOSSISTEMAS DA COSTA SUL E SUDESTE BRASILEIRA: SINTESE DOS CONHECIMENTOS, Cananéia, 1987. São Paulo, Academia de Ciências do Estado de São Paulo. v. 3. p.304-324.

MARTIN, L.; SUGUIO, K. \& FLEXOR, J.-M. 1987. Flutuaçöes do nível relativo do mar no Quaternário e seu papel na sedimentação costeira: exemplos brasileiros. In: SIMPÓSIO SOBRE ECOSSISTEMAS DA COSTA SUL E SUDESTE BRASILEIRA: SINTESE DOS CONHECIMENTOS, Cananéia, 1987. São Paulo, Academia de Ciências do Estado de São Paulo. v.1. p.40-41.

McLACHLAN, A. 1983. Sandy beach ecology - a review. In: McLachlan, A. \& Erasmus, T. eds. Sandy beaches as ecosystems. The Hague, Dr. W. Junk. p. 321-380. 
MEDEIROS, L. R. A. 1987. Conhecimento sobre meiobentos no Brasil e relato de um caso da costa sudeste-sul. In: SIMPÓSIO SOBRE ECOSSISTEMAS DA COSTA SUL E SUDESTE BRASILEIRA: SÍNTESE DOS CONHECIMENTOS, Cananéia, 1987. São Paulo, Academia de Ciências do Estado de São Paulo. v.1. p.348-379.

1989. Meiofauna de praia arenosa da ilha Anchieta, São Paulo. Dissertação de mestrado. Universidade de São Paulo, Instituto de Biociências. xxii +388 p.

1990. Meiofauna de praias arenosas marinhas. In: SIMPÓSIO DE ECOSSISTEMAS DA COSTA SUL E SUDESTE BRASILEIRA: ESTRUTURA, FUNÇĀO E MANEJO, Águas de Lind6ia, 1990. São Paulo, Academia de Ciências do Estado de São Paulo. v. 4, p.160-196.

MESQUITA, A. R. \& HARARI, J. 1983. Tides and tides gauges of Cananeia and Ubatuba - Brazil (Lat. $24^{\circ}$ ). Relat. int. Inst. oceanogr. Univ. S Paulo, (11):1-14.

\& LEITE, J. B. de A. 1986. Sobre a variabilidade do nível médio do mar na costa sudeste do Brasil. Revta bras. Geofis., 4(2):229-236.

MONTAÑO-LEY, Y. \& GUTIÉRREZ-ESTRADA, M. 1987. Control de perfiles de playa en Mazatlán, Sin., México. An. Inst. Cienc. Mar Limnol., Univ. nac. autón. Méx., 14(1):1-12.

PÁEZ-OZUNA, F.; FONG-LEE, M. de L. \& FERNÁNDEZ-PEREZ, H. 1984. Comparación de tres técnicas para analizar materia orgánica en sedimentos. An. Inst. Cienc. Mar Limnol., Univ. nac. aut6n. Méx., 11(1):257-264.

PALMER, M. A. 1988. Dispersal of marine meiofauna: a review and conceptual model explaining passive transport and active emergence. Mar. Ecol.-Prog. Ser., 48(1):81-91.

POLLOCK, L. W. 1971. Ecology of intertidal meiobenthos. Smithson. Contr. Zool., 76:141-146.

RETIÈRE, C. 1968. Contribution à l'étude de la macrofaune annelidienne de la Plage de Lancieux (Côtes-du-Nord). Bull. Lab. marit. Dinard, 1(1):5-63.

SHORT, A. D. 1983. Sediments and structures in beach nearshore environments, South East Australia. In: McLachlan, A. \& Erasmus, T., eds. Sandy beaches as ecosystems. The Hague, Dr. W. Junk. p. 145-155.
SHORT, A. D. 1984. Beach and nearshore facies: Southeast Australia. Mar. Geol., (60):261-282. .

\& WRIGHT, L. D. 1983. Physical variability of sandy beaches. In: McLachlan, A. \& Erasmus, T., eds. Sandy beaches as ecosystems. The Hague, Dr. W. Junk. p. 133-144.

SIGNORINI, S. R. 1974. Relatório das condiçōes oceanograficas nas proximidades da Ilha Anchieta. In: FUMEST, São Paulo. Ilha Anchieta: plano geral de exploração turística. São Paulo, Secretaria de Esportes e Turismo. p. 29. (divulgaçâo restrita).

SILVA, J. F. da. 1984. Dados climatologicos de Cananéia e Ubatuba (Estado de São Paulo). Bolm climatol. Inst. oceanogr., S Paulo, (5):1-18.

SUGUIO, K. 1973. Introdução à sedimentologia. São Paulo, Edgard Blücher. xiii +317 p.

1980. Rochas sedimentares: propriedades, gênese, importância econômica. São Paulo, Edgard Blücher. xix +500 p.

\& MARTIN, L. 1978. Quaternary marine formations of the States of São Paulo and southern Rio de Janeiro. In: INTERNATIONAL SYMPOSIUM ON COASTAL EVOLUTION IN THE QUATERNARY, São Paulo, 1978. Special Publication, $\mathrm{n}^{2} 1.55 \mathrm{p}$.

$$
\text { \& }
$$
1987. Classificação de costas e evoluçáo geológica das planícies litorâneas Quaternárias do sudeste e sul do Brasil. In: SIMPÓSIO SOBRE ECOSSISTEMAS DA COSTA SUL E SUDESTE BRASILEIRA: SÍNTESE DOS CONHECIMENTOS, CananÉia, 1987. São Paulo, Academia de Ciências do Estado de São Paulo. v.1, p.1-28.

VERNBERG, W. B. \& COULL, B. C. 1981. Meiofauna. In: Vernberg, F.J. \& Vernberg, W. B., eds. Functional adaptations of marine organisms. New York, Academic Press. p. 147-177.

WIESER, W. 1975. The meiofauna as a tool in the study of habitat heterogeneity. Ecophysiological aspects. A review. Cah. Biol. mar., 16(5):647-670.

WILSON, K. 1983. Beach sediment temperature variations through depth and time. Estuar. coast. Shelf Sci., 17(5):581-586.

(Manuscrito recebido 16 agosto 1991; revisto 29 julho 1992; aceito 12 novembro 1992) 